\title{
ANCHIETA E A LITERATURA BARROCA EM LATIM
}

\author{
Leodegário A. de Azevedo Fllho
}

RAMALHO, Américo da Costa. "O Inferno no De Gestis Mendi de Saa de Anchieta". In: ..... Afecto às letras, homenagem da literatura portuguesa contemporânea a Jacinto do Prado Coelho. Lisboa, Imprensa Nacional/Casa da Moeda, 1984, p. 49-57.

No artigo acima indicado, de autoria do ilustre professor Américo da Costa Ramalho, da Universidade de Coimbra, es. crita com muita convicção e autoridade, logo de inicio se lê: "O De Gestis Mendi de Saa é um poema renascentista, não apenas pela época em que foi escrito, mas pelo esquema, construção, vocabulário e espirito do Renascimento."

Há aqui três questões a discutir. A primeira é que não se pode atribuir a Anchieta, como se faz desde o título do artigo, o poema De Gestis Mendi de Saa, sem antes discutir o sério problema autoral, pelo menos à luz do ensaio "O poema de Mem de Sá e a pseudo-autoria do Padre José de Anchieta", publicado pelo Padre Serafim Leite, S.J., autor da monumental História da Companhia de Jesus no Brasil, no v. LXXVI, n. ${ }^{\circ}$, da revista Brotéria, em Março de 1963. A segunda se refere à época, segunda metade do século XVI, quando o Renascimento já estava em crise, abrindo-se então espaço para o entre-lugar do Maneirismo, sobretudo nas obras dos humanistas cristãos. $E$ a terceira diz respeito ao espirito pagão do Renascimento, inteiramente rejeitado no poema, que foi escrito na linha barroca da Contra-Reforma, como hoje só desconhecem os que não sabem distinguir os conceitos modernos de Renascimento, Maneirismo e Barroco.

Em seguida, escreve o professor Costa Ramalho, depois de declarar, com muita segurança afirmativa, que "está convencido" de que o poema é de Anchieta: "Estamos hoje longe, felizmente, do primarismo que no meu tempo de estudante liceal, aos treze ou catorze anos de idade, ainda andava por compéndios de História: a Idade Média teocêntrica; o Renascimento antropocêntrico. $O$ homem de Quinhentos de costas para Deus e para os problemas religiosos." 
Primarismo por quê? A despeito da presença do mundo antigo na Idade Média, ao contrário do que pensava Burckhardt e como se pode ver no livro La grande clarté du Moyen Age, de Gustave Cohen, sabe-se hoje perfeitamente que, nos tempos medievais, o que predominou foi a cultura religiosa, alimentada pelo pensamento cristão, para o qual toda verdade era de essência divina (e não simplesmente terrena), viesse da Antiguiidade ou da Biblia. Dai o sentido altamente espiritual da Idade Média, justificando-se assim a expressão "hưmanismo teocêntrico", já que o ideal de perfeita felicidade se buscava em Deus e nāo no mundo material. Parece que isso foi ensinado ao professor Costa Ramalho desde os tempos de liceu, sem que ele assimilasse a lição. Como lhe devem ter ensinado também que o Renascimento, por sua exagerada confiança nas forças naturais do homem, medida ou parâmetro de todas as coisas, revitalizou o "humanismo antropocêntrico", deixando-se infiltrar pelo neopaganismo da época. $E$ isso graças à leitura e à tradução dos grandes autores greco-latinos, centrando-se os valores éticos e estéticos do Renascimento no próprio homem e na sua natureza e condição terrenas. Assim, primarismo nos parece a confusão de tudo isso com a idéia empirica de que o homem de Quinhentos vivia de costas para Deus e para os problemas religiosos, absurdo que supomos jamais alguém tenha escrito. $O$ que se diz e está nos grandes teóricos da Idade Média, do Renascimento, do Maneirismo e do Barroco, com percuciente análise dos fenômenos históricos e culturais, é que o feudalismo cristão da Idade Média foi marcado por alto sentido espiritual, assim como o racionalismo e o experimentalismo da cultura renascentista se deixaram impregnar de valores terrenos e pagāos, em contacto com a própria cuitura do mundo antigo. Por isso mesmo, causa enorme estranheza a aproximação, feita pelo professor Costa Ramalho, entre Anchieta, um escolástico, e Desidério Erasmo, um herético. E tal aproximação realmente foi feita, na p. 49 da obra citada, em nítida visāo sincrética do problema, pela qual seria muito difícil proceder-se à análise que se espera da critica da cultura, antes mesmo de chegar-se a uma critica universitária abrangente. Aliás, nāo se pode confundir o sincretismo nāo raro existente no processo de criaçāo artística com nenhuma forma de sincretismo critico, pois o processo de criaçāo necessariamente difere do procedimento analítico da critica. Não admira, assim, que autores modernos venham apontando, exatamente na obra de Erasmo, a presença de fraturas maneiristas.

Em seguida, escreve o professor Costa Ramalho, sempre muito seguro de si mesmo, segurança que nāo encontramos 
na obra dos graindes especialistas da época em questão: "Mas voltemos ao Poema dos Feitos de Mem de Sá. Deus Trino e Uno é nele a força que preside aos destinos do homem. Todavia, comc em qualquer outro poema do Renascimento, as manifestaçōes do poder divino são expressas no vocabulário pagão da poesia latina: Virgilio sobretudo, depois dele, Ovídio, Lucano, Horário, por ali andam em ecos e reminiscências. $\mathrm{E}$ também o vocabulário dos poetas novilatinos portugueses dos meados do século XVI."

Aqui as afirmações são ainda mais graves. De início, porque o uso do latim de imitação clássica não faz do texto, necessariamente, um poema do Renascimento. No mesmo latim imitativo foram escritos textos literários ao longo dos séculos XVII e XVIII, que vão além da época renascentista propriamente dita. Depois, porque os jesuitas (na hipótese de ser um jesuita o autor do poema), que eram humanistas barro. $\cos$, conheciam tāo bem o latim da época áurea romana quanto qualquer humanista do Renascimento. No caso, se os jesuítas recorreram ao vocabulário pagão da poesia latina, não o fizeram dentro da perspectiva renascentista, que buscava analisar o homem em sua condiçāo terrena, a partir mesmo das expressōes artes humanitatis e litterae humaniores (Ci. cero), mas como instrumento lingüistico posto a serviço do ideal estético da Contra-Reforma, inteiramente voltado para a essência divina do homem. Nem se pode, pelo menos em nossos dias, confundir lingua com literatura, pois bem se sabe que o mesmo sistema lingüístico pode ser utilizado para exprimir realidades culturais bem diversas. Assim, o uso do vocabulário pagão da poesia latina no poema, que a tradiçāo vem atribuindo a Anchieta, não transforma o seu autor num humanista do Renascmento, como outrora se pensava e se ensinava nos velhos liceus portugueses e nos velhos ginásios brasileiros da primeira metade do nosso século, pois a questão é muito mais complexa. Nem há, literalmente falando, qualquer influência de Horácio, autor predileto do Renascimento (et pour cause), nas poesias de Anchieta em latim ou em qualquer uma das línguas utilizadas pelo missionário. $\mathbf{E}$ não há porque Horácio, com a temática do carpe diem, valorizando o momento que passa, por ser breve a vida, se voltou para a fruição dos prazeres terrenos, como autor pagāo, em sentido diametralmente oposto à visão teocêntrica (jamais antropocêntrica!) de Anchieta. Com efeito, para o piedoso jesuita, que a Igreja em breve deve canonizar, se é curta e ilusória a passagem do homem pela terra, deve-se então procurar a verdadeira felicidade $\mathrm{cm}$ Deus, asceticamente. A propósito, vejam-se os seguintes versos de seguidilha, com texto criticamente estabelecido pelo professor Silvio Elia, no 
livro As Poesias de Anchieta em Portuguès (Rio de Janeiro, Antares/Instituto Nacional do Livro, 1983), composição das páginas 62-63:

Não ay cousa segura, tudo quanto se vê se vai passando, a vida não tern dura, o bem se vai gastando, toda criatura passa voando.

Em Deus, meu Criador, está todo meu bem e esperança, meu gosto e meu amor e bem-aventurança; quem serve a tal Senhor não faz mudança.

Contente assi minha alma do doce amor de Deus toda ferida, o mundo dexa em calma, buscando a outra vida, na qual deseja ser toda absorbida.

Do pé do sacro monte, meus olhos levantando ao alto cume, vi estar aberta a fonte do verdadeiro lume que as trevas do meu peito todas consume.

Correm doces licores das grandes aberturas do penedo; levantam-se os errores, levanta-se o degredo e tira-se a amargura do fruito azedo.

Ao contrário da concepção epicurista de vida, própria do carpe diem horaciano, em Anchieta há clara renúncia aos prazeres mundanos e busca ansiada de Deus. Em Horácio, 
porque a vida $\dot{e}$ breve, devemos aproveitar todos os momentos que passam. Em Anchieta, exatamente porque a vida é breve, não temos que nos comprometer com a precariedade do mundo terreno. Aliás, conforme documento que se encontra no Instituto Histórico e Geográfico Brasileiro (L. 120, manuscrito 2105), o texto apresenta o seguinte e sugestivo título: "Da vaidade das cousas do mundo", desde aí configurando-se a posição anti-horaciana do autor. Assim, logo na primeira sétima da seguidilha, o tempo humano é sentido como um contínuo desfazer-se, pois toda criatura passa voando. Portanto, na curta passagem do homem pela terra não há coisa segura, encontrando-se a verdadeira felicidade apenas na vida eterna, pois toda esperança está em Deus e não no mundo material. E tirar "a amargura do fruito azedo" representa a própria libertação espiritual pela morte, num mistico anseio, todo o texto ajustando-se muito bem à seguinte consideração teórica de Vítor Manuel de Aguiar e Sil. va, so que parece não suficientemente lido em Coimbra:

O tema da fugacidade do tempo, da ilusão da vida e das coisas munclanas ocupa um lugar central na literatura barroca. As motivaçōes religiosas deste tema são bem evidentes: trata-se de lembrar ao homen que tudo é vāo e efêmero à superfície da terra, que a vida carnal é uma passagem e que é necessário procurar uma realidade suprema, isenta de mentira e de imperfeição. As ruinas atestam a fragilidade do homem e os poetas meditam angustiados sobre a fragilidade da beleza humana, sobre a destruição e o vazio que esperam tudo o que é grácil e luminoso. (Teoria da Literatura, Coimbra, Almedina, 1973, p. 422 ).

Literalmente, não é outra a posição espiritual que se en. contra nos grandes e pequenos poemas latinos de Anchieta, como aliás na seguidilha transcrita e no resto de sua obra em espanhol, em português e em língua geral da costa brasileira a seu tempo. $E$ falar em Horácio, diante de tudo isso, é muito pior do que um ato impensado... Até porque a simples presença de formas linguiísticas coincidentes nada tem a ver com influência literária.

Mas sempre com a mesma autoridade e a mesma convicção, realmente inusitadas nos grandes especialistas europeus ou americanos, por nós lidos, o professor Costa Ramalho afirma ainda que Anchieta usou "o vocabulário dos poetas novilatinos portugueses dos meados do século XVI." Mas, apesar da generalizaçāo, como prova, cita apenas um simples 
vocábulo (Lysiades), que ele peremptoriamente declara ter vindo de André de Resende para o poema sobre os feitos de Mem de Sá. Em momento algum, entretanto, lhe ocorreu a hipótese muito mais viável ou aceitável de que o autor do poema, seguindo a deriva da lingua na época, também tivesse criado o vocábulo, à semelhança do que fez André de Resende. Note-se que o autor do poema, ao lado de Lysiades, usa Christiades, ciuas criações verbais. A propósito, veja-se o verbete "Lusitânia" no Dicionário Etimológico de Antenor Nas. centes. Aliás, toda a gente sabe que não existe nenhuma prova de que Anchieta tivesse lido qualquer autor da chamada literatura novilatina do Renascimento. Ao contrário disso, como professoi de latim no Colégio dos Jesuitas de Sāo Paulo de Piratininga, apesar das imensas dificuldades bibliográficas naquela época, comprovadamente leu e traduziu Virgilio e Ovídio, entre outros autores da época áurea de Augusto, mas não autores novilatinos do Renascimento. Por isso mesmo, o que importa aqui é o estudo da criação verbal em todo o poema, pois o seu autor habilmente soube amoldar a lingua latina à realidade brasileira daquela época. $E$ esse estudo é que esperávamos da competência do professor Costa Ramalho, inegavelmente um grande latinista, quando pusemos em suas mãos a obra de Anchieta, pois aqui a busca da diferença vale mais do que a busca de identidades forçadas.

Por outro lado, se Deus é Tonans (trovejante), como Júpiter na Eneida de Virgilio, ou Rex Coeli, Rex Supernus e Magni Fabricator Olympi, nisso nada há que admire, já que em língua indigena brasileira o mesmo Deus é Tupã (Tupã amó èunãngatú moñángi, igual a Deus criou uma santa). Na verclacle, e isso é o que vale do ponto de vista literário, Anchieta recorreu ao vocabulário pagão da poesia latina, como recorreu ao vocabulário também pagão e mitico do folclore indigena brasileiro, para negar os valores do paganismo $e$ para transmitir a sua fé absoluta no Cristo, venerando a Virgem Maria e adorando o Criador. Não se tem, assim, que enfatizar, em sua obra, nenhuma "riqueza mitológica renascentista", como não se tem que superestimar nenhuma riqueza mitológica indigena. Aliảs, tudo isso foi imediatamente percebido pelo Padre Armando Cardoso, S.J., na inteligente tradução que fez da obra de Anchieta, sem exagerar a importância de "mitónimos greco-latinos" ou de quaisquer mitos indigenas, pois tudo isso foi largamente submetido, pelo próprio autor dos textos, a um processo de cristianização permanente. Por isso, algumas vezes, a substituição feita pelo Padre Armando Cardoso, S.J., de termos ou expressões miticas por paráfrases adequadas, muito longe de violentar o poema, simplesmente respeita o alto sentido religioso de que 
toda a obra se reveste. Do contrário, imaginemos um tupinólogo ortodoxo, lendo as poesias em tupi e inteiramente voltado para a mitologia dos Tupinambas da costa brasileira. Certamente, escapará ao tupinólogo que o sacerdote recorreu à língua dos índios como instrumento de propagação da fé cristā, sem qualquer compromisso com a cultura indígena propriamente dita. $\mathrm{E}$ teremos então o correspondente da leiture proposta pelo professor Costa Ramalho para os textos em latim. Aliás, o especialista português chega ao ponto de criticar a tradução feita pelo Padre Armando Cardoso, S.J., ao comental outro texto, nos seguintes termos: "Infelizmente, o Senhor Pe. Armando Cardoso reduz toda esta riqueza mitológica renascentista ao denominador comum, algo prosaico, de Sol e Aurora."

Ora, sem sombra de qualquer dúvida, o Padre Armando Cardoso, S.J., é que está certo e não o professor Costa Ramalho, que se revele impenetravel ao sentido religioso dos textos literários de Anchieta, voltando-se exageradamente pa10. a mitologia pagã da Antiguiidade greco-latina. Chega mesmo a falar em influências de Horácio, como já vimos, o que representa um verdadeiro contra-senso de interpretação literária. E segue o seu raciocínio: usa Marte, para a guerra; Vulcano, para o fogo; Neptuno, para o mar; e Lyaeus, para 0 vinho.

E dai?

Todo o vocabulärio pagão da poesia latina de Anchieta está sendo utilizado como instrumento de difusão da fé católica, de acordo com o programa artístico da Contra-Reforma, sem qualquer compromisso com o paganismo. Assim, para designar o Inferno, ao lado de Lucifer (vocábulo que Ancinieta usava em portugués como oxítono e não como proparoxitono) ou Satanás, aparecem também e até com mais frequiencia, sein que isso tenha qualquer importância pagã, muito pelo contrário, os nomes de Tártaro, Estígio ou Flegetonte. Do mesmo modo, o jesuíta empregou a palavra Olympus (e também Caelum) para designar o céu, como recorreu à palavra Tupã para designar Deus nas poesias em tupi. Nos dois casos, o do latim e o da lingua indigena brasileira, como é evidente, o processo de cristianização vocabular é indispensável à verdadeira compreensão do texto. Em latim, depois de convocar numerosos mitônimos grecolatinos (e quanto maior for a concentração vocabular tanto melhor), para exorcizá-los diante da face luminosa do Cristo, o autor do poema concluiu, nos versos 1173 e 1174 da estrofe em questão:

Squameus umbrosae Chaos in poenale Gehennae A Facie, Rex Christie, tua, collabitur Anguis. 
Para esses versos, o Padre Armando Cardoso propôs a seguinte tradução:

Foge da tua face, ó Cristo Rei, a escamosa serpente e sepulta-se na treva justiceira da eterna geena.

Não satisfeito, o professor Costa Ramalho propōe em texto corrido:

A serpente escamosa da sombria Gehena desliza para o Caos punitivo, fugindo da tua face, ó Cristo-Rei!

Pode ser que a segunda tradução (aliás sem necessidade do grafema - $h$ - em Gehena, pois o mesmo grafema não aparece em Caos) esteja mais apurada que a primeira, mas o sentido religioso do texto permanece o mesmo, pois todos os mitos greco-latinos são sempre afugentados pela visão sublime do Cristo, tanto aqui como ao longo do poema. No fundo, tais mitos pagãos são identificados com o demônio, exatamente como se fazia na Idade Média cristã, em sentido igualmente teocêntrico. Assim, os mitônimos servem de con. traste radical entre paganismo e cristianismo, numa clara situação de repulsa e não de "simbiose", como pensa e quer o professor Costa Ramalho, pois tal procedimento renascentista seria um absurdo na obra do jesuíta. Simbiose de paganismo e cristianismo há em Os Lusíadas, a exemplo da extraordinária narração feita por Camões no episódio da Ilha dos Amores, mas nunca em Anchieta. Nem há mesmo, no De Gestis Mendi de Saa, qualquer interferência de entidades mitológicas em açōes humanas, como bem observa o Padre Armando Cardoso, S.J.:

Anchieta, com muita vantagem para a sinceridade do sentimento, aparta-se do processo antigo e da moda renascentista que invoca as musas pagãs. (op. cit. p. 35).

Portanto, ao longo do poema, os mitônimos sāo identificados com Satanás e sempre fogem espavoridos diante da visão sublime do Cristo-Rei. Com isso queremos dizer que, do ponto de vista literário, quanto maior for a concentração vocabular de mitónimos, tanto melhor e mais intenso será o contraste entre paganismo e cristianismo, estabelecendo-se radical oposição entre uma coisa e outra. Com efeito, por curiosa ironia, no De Gestis Mendi de Saa, os mitônimos greco-latinos são convocados para ficar sem voz, pois todos sāo rejeitados ou afugentados pelas imagens cristās, que se trans- 
formam na verdadeira evidência do sobrenatural, negando-se assim os valores do paganismo dentro do próprio paganismo. Nāo entender isso, ou ver nisso qualquer convivência pacifica ou "simbiose" de paganismo e cristianismo, significa renunciar à própria compreensão do poema, sem dúvida alguma uma das mais perfeitas construções literárias do Anti-Renascimento ou Contra-Renascimento na América, ao tempo em que foi escrito.

Sempre em função do programa artístico emanado do Concilio de Trento, na linha barroca da Contra-Reforma, sem sombra de dúvida, foram escritos todos os versos do poema aqui discutido. Por isso é que se diz que, numa espécie de Barroco antecipado, a estética jesuitica ultrapassou o Renascimento propriamente dito. A propósito, veja-se o que escreve Hauser, sem precisar recorrer aqui ao livro Ethique et esthétique du Baroque (Paris, Actes Sud/Hubert Nyssen, 1985), de Benito Pelegrin:

As opiniōes dividem-se sobre se a expressão artistica original da Contra-Rreforma se encontra no Maneirismo ou no Barroco. (Note-se que o autor nem toca em Renascimento). O Maneirismo esta mais perto da Contra-Reforma, cronologicamente falando, e a austera atração espiritualista da época tridentina exprime-se mais puramente no Maneirismo do que no Barroco voluptuoso. Mas o programa artístico da Contra-Reforma, a propagação do Catolicismo por meio da arte, entre as grandes massas da população, é conseguida em primeiro lugar pelo Barroco. É óbvio que o que estava no espírito do Concilio de Trento não era uma arte que, tal como o Maneirismo, apelasse simplesmente para a fina camada dos intelectuais, mas uma arte do povo, tal como de fato se tornou o Barroco. Na época do Concílio, o Maneirismo era a forma de arte mais espalhada e mais viva, mas não representava de modo algum a orientação mais adequada para resolver os problemas artísticos da Contra-Reforma. O fato de que tinha que ceder ao Barroco explica-se, sobretudo, pela inabilidade em dominar tarefas eclesiásticas, encomendadas à arte pela Contra-Reforma. (História social da arte e da cultura. Lisboa, Jornal do Foro, 1954, v. I, p. 484).

Felizmente, como acima se vê, já vai muito longe o tempo em que se ensinava, em liceus c ginásios do princípio do nosso século, que tudo isso era Renascimento. Hoje, com 
efeito, a partir mesmo da revolução de conceitos introduzida por Wölfflin, já lá se vão décadas, e isso para nāo citar os mais recentes teóricos do Maneirismo, como Weise, os especialistas realmente atualizados já não incorrem em tais confusões.

Em síntese, nas origens da literatura brasileira coube à Companhia de Jesus esterilizar o espirito do Renascimento, abrindo-se então espaço para a literatura contra-renascentista da estética jesuítica. Assim, a literatura anchietana só não foi maneirista porque o missionário se afastou desse estilo refinado e aristocrätico, para exprimir-se em Barroco. Isso mesmo está ainda em Helmut Hatzfeld, quando analisa o caráter ascético do humanisino barroco, em seus Estudios sobre el Barroco, Madrid, Gredos, 1964, p. 133. Portanto, a tradição medieval cristā, alterada pelo Renascimento, revitalizou-se com o Barroco, após a crise instaurada pelo Maneirismo, ambos os estilos distanciando-se do experimentalismo e do racionalismo do Renascimento. $E$ se o Barroco apenas se realizou plenamente no século XVII, como se pode ver em Vieira, aliás outro jesuita, nem por isso deixou de apontar os seus antecedentes na segunda metade do século XVI, a partir da crise provocada pelo Maneirismo, mas sobretudo com a estética jesuítica. E a compreensāo dessa estética jesuítica como arte da Contra-Reforma não é nenhuma novidade, pois já foi analisada por Weisbach, há muito e muito tempo.

Compreendemos as dificuldades teóricas do professor Costa Ramalho, em sua leitura limitada aos mitônimos latinos e incapaz de penetrar na análise literária do texto, pois é apenas um latinista e não um critico de literatura. Mas insistimos em que, no De Gestis Mendi de Saa, o que se tem é a configuração da realidade brasileira daquela época em termos de um "naturalismo barroco" (a expressão é de Lafuente Ferrari), pois este era o estilo mais adequado a exprimir, em sua pujança. o drama da catequese do silvicola, a posse sangrenta da terra e a vitória contra a invasāo dos franceses. No poema, ultrapassando-se completamente a órbita renascentista, sāo inegáveis a habilidade e o espírito criativo do autor, que se valeu da língua de Virgilio e de Ovídio para representar cenas cruéis e selvagens, como se pode ver na descrição do episódio antropofágico em que o Bispo $D$. Pero Fernandes Sardinha foi deglutido pelos índios Caetés. $\mathrm{E}$ isso nada tem a ver com a temática em geral sofisticada e aristocrática da chamada literatura novilatina portuguesa da mesma época, aløumas vezes simples pastichos (passe $o$ galicismo) dos autores da época áurea romana. De nossa parte, não temos dúvida de que a língua latina do poema 
possa ser comparada, do ponto de vista do vocabulário e das convenções métricas, com a lingua latina usada pelos humanistas portugueses do Renascimento, pois as fontes linguísticas eram as mesmas. Mas nāo é de língua que falamos, nem de convençōes métricas, e sim de uma literatura extremamente original em sua temática brasileira, como fruto do programa artístico da Contra-Reforma na América. Assim, no De Gestis Mendi de Saa, vale muito mais a análise da criatividade verbal do autor, na sua ânsia cristā de interferir na realidade cultural do Mundo Novo, do que simplesmente forçar identidades vocabulares, aliás muito discutiveis, com autores novilatinos portugueses. Afinal de contas, a busca da diferença e não a busca da identidade é que vai marcar a origem da nossa literatura, numa fase inicial de concorrência ou de confluência linguística, pois, naquela altura, o português ainda não se havia implantado como língua nacional do Brasil. $\mathrm{E}$ a conciusão de tudo isso é muito simples: o repertório crítico do professor Américo da Costa Ramalho, competente latinista e investigador de dados biográficos e historicistas do século XVI, não está suficientemente alimentado para a discussāo universitária de questões ligadas à teoria da literatura, à história geral clas artes e à crítica da cultura, a despeito da desenvoltura e da segurança afirmativa com que escreve sobre tais assuntos, ao contrário do que se vê na obra dos grandes especialistas modernos. 